\section{Drug treatment and rehabilitation in China: Theoretical rationales and current situations}

\author{
Gloria Yuxuan Gu* and Hua Zhong
}

The Chinese University of Hong Kong, Hong Kong

\section{Introduction}

Global drug use has reached epidemic levels, with approximately 269 million drug users worldwide [1]. Problematic drug use may lead to serious physical, social, and mental health problems. An estimated 167,000 deaths attributed to drug-related disorders worldwide in 2017 [2]. The rising global drug use and its severe adverse consequences make the drug treatment/rehabilitation a top priority for policymakers. In modern China, illicit drug use has raised great concern from both the academia and the public. Nearly 2.15 million Chinese were registered as drug users in 2019 [28]. Drug-related crimes and deaths are also increasing [29]. The current drug treatment programs in China are mainly compulsory, addressing coercion and discipline. However, the effectiveness was found to be low [3]. Situated in the fields of social work, public health, and psychology, Chinese scholars and practitioners have conducted some empirical tests for these drug treatment/rehabilitation programs and already found several effective preventive factors in the programs. However, the existing research on the design and evaluation of Chinese drug treatment/rehabilitation programs rarely investigate the theoretical rationales behind these programs. This study would address three criminological theories that have been applied to explain drug treatment and rehabilitation in Western societies: Differential Association Theory, Social Bonding Theory, and Labeling Theory. Similar theoretical rationales could be learnt and adopted by Chinese programs.

\section{Potential theoretical rationales}

Differential Association Theory: Differential Association Theory argues that people acquire criminality from the others they associate with. Sutherland has highlighted that if individuals are frequently exposed to law-violating definitions for a longer time and with greater intensity, they are more likely to deviate from the law [4,5]. Akers' social learning propositions expand Sutherland's theory and provide a more comprehensive perspective. Accorder to Akers, the crime learning process mainly contains three mechanisms:

\author{
More Information \\ *Address for Correspondence: \\ Gloria Yuxuan Gu, Department of Sociology, The \\ Chinese University of Hong Kong Shatin, Hong \\ Kong, Tel: +852 67627221; \\ Email: gloria.gu.yuxuan@outlook.com; \\ gloriagu@link.cuhk.edu.hk \\ Submitted: February 01, 2021 \\ Approved: February 17, 2021 \\ Published: February 18, 2021 \\ How to cite this article: Gu GY, Zhong H. Drug \\ treatment and rehabilitation in China: Theoretical \\ rationales and current situations. J Addict Ther \\ Res. 2021; 5: 009-011. \\ DOI: 10.29328/journal.jatr.1001015 \\ Copyright: (c) 2021 Gu GY, et al. This is an open \\ access article distributed under the Creative \\ Commons Attribution License, which permits \\ unrestricted use, distribution, and reproduction \\ in any medium, provided the original work is \\ properly cited. \\ A) Check for updates \\ (6) OPEn ACCESS
}

reinforcing deviant behavior, adopting beliefs conducive to deviant behavior, and imitating deviant patterns [6].

In applying this framework to drug rehabilitation, international studies have provided empirical evidence that thereduction of affiliation with addicted peers plays a primary role in the effective drug treatment and recovery process $[7,8]$. For instance, Weiss and his colleagues have demonstrated why the learning principle is useful in cocaine therapeutic communities [9]. Through mutual-help group attendance and participation, the treated drug users could be segregated from drug subculture and assimilate into an anti-drug group; gradually, their learning definitions become favorable to lawabiding values and behavior. Prior literature published in Chinese journals also has revealed the relationship between the refusal of drug-addicted peers and positive outcomes of drug rehabilitation $[10,11]$. However, these studies generally lack the theoretical insights.

Social Bonding Theory: Hirschi's Social Bonding Theory suggests that motivations to commit deviant and criminal behaviors intrinsically exist within individuals; social bonding, thus, is regarded as a determinant of obeying the social and legal norms to refrain from individuals' natural crime motivation [12,13]. People with strong social bonds are less likely to engage in criminal behaviors because they are more sensitive to the others' opinions and fear the corresponding social consequences. Hirschi has formulated four elements 
of social bonding: attachment, belief, involvement, and commitment [12].

In western countries, previous studies on drug treatment have consistently demonstrated that establishing pro-social bonds could reduce illicit drug use $[14,15]$. For example, Knight and Simpson's study in the United States has identified that family is an essentiallocus of socialbonding [16].Beingaccepted by their family is a key element of treatment that enables drug users to re-embed in a conventional social network, thereby maintaining an abstinent life. Different from the individualistic Western culture, China has a collectivist cultural orientation, which may contribute to a more significant role played by social bonding. Some evidence has emerged among the handful studies that address the relationship between conventional social bonds and positive drug treatment outcomes in China $[17,18]$. Unfortunately, these studies either have very small sample size or are unable to theoretically explain why social bonding is important.

Labeling Theory: Labeling Theory posits a symbolic interactionism perspective and argues that criminal and deviant behaviors are socially constructed through stigmatizing labels. Becker has proposed that the discrediting labels, named by the agents of control, are risk factors of crime and deviance $[19,20]$. The formation of an individual's self-concept and action reflects the tags given by the others [19]. Individuals might experience higher risks of behaving in accordance with their tags, which means people labeled as 'criminals', 'addicts', 'delinquents' are more likely to commit such behaviors.

Proponents of this theory argue that the key factor in rehabilitating drug addicts is transforming their 'addict identity' to 'ordinary identity' $[21,22]$. Existing empirical studies have found the stigmatization process surrounding drug users is a shared problem, leading to the social exclusion of drug users and constituting obstacles to treatment and rehabilitation $[23,24]$. Several descriptive studies in China also have implicitly indicated the relationship between perceived stigma and the negative outcomes of drug rehabilitation $[25,26]$. Yang and his colleagues have found that the interviewees report continual stigmatization from the public and the police after their drug rehabilitation; such degradation experiences appear to disrupt their normal lives, reducing the effectiveness of the treatment programs [27].

\section{Current situations of drug treatment and rehabilitation} in china

In the Chinese context, illicit drug use has long been negatively regarded as a type of severe deviant behavior, which means harm reduction efforts are mainly applied to reduce social harms caused by drug use rather than harms to the users themselves [30]. As we mentioned before, drug treatment programs in China are often compulsory and run in confinement [29]. Specifically, the dominant treatment approach is practiced through compulsory institutional rehabilitation with labor, aiming to minimize the social harm of drug use by separating drug users from the mainstream society and socializing them with mainstream norms [31]. However, the outcome is not that satisfactory and attracts a lot of criticism [29]. In recent years, to address the inadequacy of institutional treatment, the communitybased drug treatment and health-oriented harm reduction programs, mainly consisted of vocational training and psychoeducational training, have been introduced as alternatives $[32,33]$. However, such community-based treatments are also criticized for being unprofessional and lack of theoretical foundation. Solid theoretical frameworks are urgently needed to guide more nuanced approaches to drug treatment design and assessment in China. That is, before we develop any treatment/rehabilitation programs, we need to understand how and why drug users can be effectively supported to reduce their likelihood of relapse.

\section{Conclusion}

The studies of drug treatment and rehabilitation in China have only been developed in recent decades and still in their infancy. Most of them are oversimplified or have limited theoretical discussions. Three potential theoretical frameworks: Differential Association Theory, Social Bonding Theory, and Labeling Theory were reviewed here and would be inspiring for future research on drug treatment and rehabilitation in the Chinese context. We are looking forward to more in-depth and systematic explorations toward effective drug treatment and rehabilitation programs to help Chinese drug users.

\section{References}

1. United Nations Office on Drugs and Crime. World drug report 2020. https://wdr.unodc.org/wdr2020/field/WDR20_BOOKLET_1.pdf

2. GBoDC N. Global burden of disease study 2017 (GBD 2017) sociodemographic index (SDI) 1950-2017. Seattle, United States Inst Heal Metrics Eval. 2018.

3. Simpson DD, Sells SB. Effectiveness of treatment for drug abuse: An overview of the DARP research program. Adv Alcohol Subst Abuse. 1982; 2: 7-29.

4. Sutherland E, Cressey D. Criminology, eight edition. Philadelphia/New York/Toronto: JB Lippincott Company; 1970.

5. Goff C, Gilbert G. Edwin H. Sutherland: The Development of Differential Association Theory. In: The Origins of American Criminology. 2018.

6. Akers RL. Criminological theories: Introduction and evaluation. Routledge. 2013.

7. Karakos HL. Positive peer support or negative peer influence? The role of peers among adolescents in recovery high schools. Peabody $\mathrm{J}$ Educ. 2014; 89: 214-228.

PubMed: https://pubmed.ncbi.nlm.nih.gov/24839335/

8. McKay JR, Van Horn D, Rennert L, Drapkin M, Ivey M, et al. Factors in sustained recovery from cocaine dependence. J Subst Abuse Treat. 2013; 45: 163-172.

PubMed: https://www.ncbi.nlm.nih.gov/pmc/articles/PMC3696509/

9. Weiss RD, Griffin ML, Gallop RJ, Najavits LM, Frank A, et al. The effect 
of 12-step self-help group attendance and participation on drug use outcomes among cocaine-dependent patients. Drug Alcohol Depend. 2005; 77: 177-184.

PubMed: https://pubmed.ncbi.nlm.nih.gov/15664719/

10. Liu L, Huijuan D. Research on the maintenance of drug use behavior by Chinese female drug users. Population and Development 2015; 4-81.

11. Xuelian Z. Anomie and Regression: A Sociological Analysis of Criminal Sociology of Young Women's Drug Abuse Career Exit. Chinese Youth Studies. 2020; 73-79.

12. Hirschi T. A control theory of delinquency. Criminol theory Sel Class Readings. 1969; 1969: 289-305.

13. Cassino P, Rogers W. Hirschi's Social Bonding Theory Nearly 45 Years Later: A comparison of a traditional, contemporary and hybrid model. Theory in Action. 2016.

14. Chapple CL, Hope TL, Whiteford SW. The direct and indirect effects of parental bonds, parental drug use, and self-control on adolescent substance use. J Child Adolesc Subst Abuse. 2005; 14: 17-38.

15. Zavala E, Spohn RE, Alarid LF. Gender and serious youth victimization: assessing the generality of self-control, differential association, and social bonding theories. Sociol Spectr. 2019; 39: 53-69.

16. Knight DK, Simpson DD. Influences of family and friends on client progress during drug abuse treatment. J Subst Abuse. 1996; 8: 417-429. PubMed: https://pubmed.ncbi.nlm.nih.gov/9058354/

17. Liu L, Wang H, Chui WH, Cao L. Chinese drug users' abstinence intentions: The role of perceived social support. J Drug Issues. 2018; 48: 519-535.

18. Xiong H, Jia J. Situational Social Support and Relapse: An Exploration of Compulsory Drug Abuse Treatment Effect in China. Int J Offender Ther Comp Criminol. 2019; 63: 1202-1219.

PubMed: https://pubmed.ncbi.nlm.nih.gov/30501427/

19. Becker HS. Outsiders: studies in the sociology of deviance. Vol. 29 New York: Free Press. 1963.

20. Bernburg, JG. Labeling theory. In Handbook on crime and deviance. Springer. Cham. 2019; 179-196.

21. Anderson TL. Types of identity transformation in drug-using and recovery careers. Sociol Focus. 1993; 26: 133-145.

22. Biernacki P. Pathways from heroin addiction: Recovery without treatment. Temple University Press; 1986.
23. Luoma JB, Twohig MP, Waltz T, Hayes SC, Roget N, et al. An investigation of stigma in individuals receiving treatment for substance abuse. Addict Behav. 2007; 32: 1331-1346.

PubMed: https://pubmed.ncbi.nlm.nih.gov/17092656/

24. Myers B, Fakier N, Louw J. Stigma, treatment beliefs, and substance abuse treatment use in historically disadvantaged communities. Afr J Psychiatry. 2009; 12: 218-222.

PubMed: https://pubmed.ncbi.nlm.nih.gov/19750251/

25. Deng R, Li J, Sringernyuang L, Zhang K. Drug abuse, HIVIAIDS and stigmatisation in a Dai community in Yunnan, China. Soc Sci Med. 2007; 64: 1560-1571.

PubMed: https://pubmed.ncbi.nlm.nih.gov/17257727/

26. Yang M, Mamy J, Gao P, Xiao S. From abstinence to relapse: a preliminary qualitative study of drug users in a compulsory drug rehabilitation center in Changsha, China. PLoS One. 2015; 10 e0130711. PubMed: https://pubmed.ncbi.nlm.nih.gov/26107639/

27. Meng J, Burris S. The role of the Chinese police in methadone maintenance therapy: A literature review. Int J Drug Policy. 2013; 24 e25-34.

PubMed: https://pubmed.ncbi.nlm.nih.gov/23623719/

28. Commission NNC. Annual report on drug-using situation in China. Natl Narcotics Control Comm. 2019

29. Liu L, Hsiao SC. Chinese Female Drug Users' Experiences and Attitudes With Institutional Drug Treatment. Int J Offender Ther Comp Criminol. 2018; 62: 4221-4235. PubMed: https://www.ncbi.nlm.nih.gov/pubmed/29478389

30. Liu L, Chui WH, Chen Y. Violent and non-violent criminal behavior among young chinese drug users: A mixed methods study. Int $\mathrm{J}$ Environ Res Public Health. 2018; 15: 432 PubMed: https://pubmed.ncbi.nlm.nih.gov/29498649/

31. Bull M, Denham G, Trevaskes S, Coomber R. From punishment to pragmatism: Sharing the burden of reducing drug-related harm. Chinese J Comp Law. 2016; 4: 300-316.

32. Liu L, Chui WH. Rehabilitation policy for drug addicted offenders in China: current trends, patterns, and practice implications. Asia Pacific J Soc Work Dev [Internet]. 2018; 28: 192-204.

33. Zhang SX, Chin KL. A People's War: China's struggle to contain its illicit drug problem. Improv Glob Drug Policy Comp Perspect UNGASS 2016; 2015; 1-15. http://www.brookings.edu/ /media/Research/Files/ Papers/2015/04/global-drug-policy/A-Peoples-War-final.pdf?la=en 